\title{
On Properties of Circuit for Circuit Evaluation as a Parallelization Procedure
}

Katsuhiro Seino Non-member (Niigata University, katsu@neuro.ie.niigata-u.ac.jp)

Ken Tanaka Member (Niigata University, tanaka@ie.niigata-u.ac.jp)

Keywords: circuit for circuit evaluation, NC, P, P-complete problem

It is shown here that if $\mathbf{N C}=\mathbf{P}, \mathbf{N C h i e r a r c h y}$ is finite. We give two proofs for it.

Proposition $1 \quad \mathbf{N C}=\mathbf{P} \Rightarrow \mathbf{N C}$ hierarchy is finite. (proof)We consider a $\mathbf{P}$-complete problem. A Turing machine with polynomial time constrain can solve it. If $\mathbf{N C}=$ $\mathbf{P}$, a NC circuit can also solve it and otherwise not. Suppose that $\mathbf{N C}=\mathbf{P}$. A $\mathbf{N C}$ circuit that solve a $\mathbf{P}$-complete problem, is considered to be a $\mathbf{N C}^{i}$ array with a specific growth rate. The fact that $\mathbf{N C}=\mathbf{P}$ and logarithmic space reductions can be executed within polynomial time, guarantees that any computation executed by NC circuit with a growth rate larger than $i$ can be executed even by the circuit with rate $i$.

We give another proof for the proposition1.
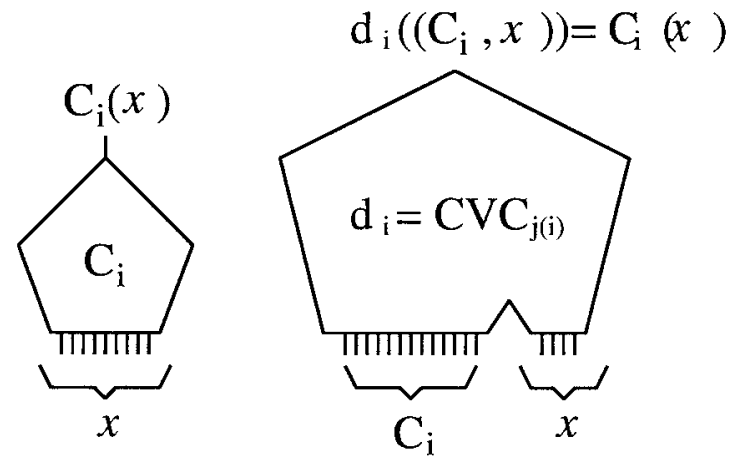

Fig. 1. Circuit for Circuit Evaluation

Proposition $\mathbf{2}$ If $\mathbf{N C}=\mathbf{P}$, there exists a generic algorithm that transduces any polynomial size circuit into a polynomial size circuit with poly-log depth.

(proof) We refer a circuit which solves the circuit evaluation problem as "circuit for circuit evaluation", indicated by $\left\{C V C_{i}\right\}$ where $i \geq 1$ and $i$ is the length of input. We represent polynomial size circuits array by $\left\{c_{i}\right\}$ and transduced circuits array by $\left\{d_{i}\right\}$, where $i \geq 1, c_{i}$ and $d_{i}$ are circuits with input length $i$.

Consider the evaluation of a circuit in $\left\{c_{i}\right\}$ by a circuit in $\left\{C V C_{i}\right\}$. A CVC, getting the description of $c_{i}$ and its input $x$, compute $c_{i}(x)$.

$$
C V C_{j(i)}\left(\left(c_{i}, x\right)\right) \equiv c_{i}(x) \text { where } j(i)=\left|\left(c_{i}, x\right)\right|
$$

We compare the complexity of $\left\{C V C_{i}\right\}$ and that of $\left\{d_{i}\right\}$. Considering $j(i)=\left|\left(c_{i}, x\right)\right|$, this array can be transduced as follows,

$$
\left\{d_{i}\right\}=\left\{C V C_{j(1)}, C V C_{j(2)}, C V C_{j(3)}, \ldots, C V C_{j(i)}, \ldots\right\}
$$

The complexity of new circuits array depends on the complexity of $\left\{c_{i}\right\}$ and $\left\{C V C_{i}\right\}$.

We indicate the complexity of $\left\{c_{i}\right\}$ as size $S(i)$ and depth $D(i)$, and the complexity of $\left\{C V C_{i}\right\}$ as size $S^{\prime}(i)$ and depth $D^{\prime}(i)$. If $j(i)=\left|\left(c_{i}, x\right)\right|$, then $\left|c_{i}\right| \in O(S(i))$. The relationship $\left|c_{i}\right|>|x|$ lead us to $j(i) \in O(S(i))$, so the complexity of $\left\{d_{i}\right\}$ is size $S^{\prime}(j(i))$ and depth $D^{\prime}(j(i))$.

When $S(i)$ is polynomial, $D(i)$ is any , $S^{\prime}(i)$ is polynomial and $D^{\prime}(i)$ is poly-log, the size of $\left\{d_{i}\right\}$ become large but its depth is within poly-log. In other words, if $j$ is a polynomial of $i, D^{\prime}$ is the order of poly-log $D^{\prime}$ in regard to $j$ and $i$.

Since Circuit Evaluation Problem belongs to $\mathbf{P}$, the assumption $\mathbf{N C}=\mathbf{P}$ implies that the circuit for circuit evaluation can be exporessed with NC circuits and the depth of $\left\{d_{i}\right\}$ is poly-log with the same power of $\left\{C V C_{i}\right\}$.

The assumption $\mathbf{N C}=\mathbf{P}$ implies that any polynomial size circuit can be transduced into a polynomial size and polylog depth circuit. Such a parallelization property can be applied not only for uniform circuits but also for non uniform circuits. This interesting property suggests that the assumption $\mathbf{N C}=\mathbf{P}$ would be false. 


\title{
回路評価回路の並列化手続きとしての性質について
}

\author{
非会員 清野 克宏* 正 員 田中 賢*
}

On Properties of Circuit for Circuit Evaluation as a Parallelization Procedure

Katsuhiro Seino*, Non-member, Ken Tanaka*, Member

It is shown here that if $\mathbf{N C}=\mathbf{P}$, NChierarchy collapses. We give two proofs for it. From the point of view of circuit for circuit evaluation, the assumption $\mathbf{N C}=\mathbf{P}$ implies that any polynomial size circuit can be transduced into a polynomial size and poly-log depth circuit. Such a parallelization property can be applied not only for uniform circuits but also for non uniform circuits. This interesting property suggests that the assumption $\mathbf{N C}=\mathbf{P}$ would be false.

キーワード : 回路評価回路 , NC , P , P 完全問題

Keywords: circuit for circuit evaluation, NC, P, P-complete problem

\section{1. まえがき}

計算複雑さの理論のなかの $\mathbf{P}$ 完全性の理論は, 大規模な 並列計算がどこまで可能かを調べることが目的のひとつに なっている。並列計算の限界を見極めれば，高速化が本質 的に困難な問題への努力を回避し，高速化が期待できる問 題へのみ傾注することができる。

$\mathrm{NC}$ は現実的な並列計算のモデルで， $\mathrm{P}$ は現実的な直列 計算のモデルである。 $\mathrm{NC}=\mathbf{P}$ ならば， $\mathbf{P}$ のすべての問 題，すなわち，現実的な直列計算て解けるすべての問題が， 現実的に並列計算できることになる。逆に $\mathbf{N C} \neq \mathbf{P}$ なら ば，P のなかに本質的に直列的な問題があることになる。 $\mathrm{NC}$ と P の真の包含性は未解決である ${ }^{(5)}$ 。

本稿では， $\mathrm{NC}=\mathbf{P}$ という仮定の含意について考える。 $\mathbf{N C}=\mathbf{P}$ を仮定したときに，回路を評価する回路という考 えが興味深い性質を導く。すなわち，構造的な制約をもつ $\mathrm{NC}$ 回路が構造的に制約のない一般の回路を評価しうる。 この性質は, $\mathbf{N C}=\mathbf{P}$ という仮定か誤りであるということ を示唆する。

\section{NC 階層}

$\mathrm{NC}$ は $\mathrm{NC}^{1} \subseteq \mathrm{NC}^{2} \subseteq \mathrm{NC}^{3} \subseteq \cdots$ というように階層 を構成するように定義される(2)。 $\mathrm{NC}=\bigcup_{k>0} \mathrm{NC}^{k}$ とな る。この定義上の階層が, 本当に階層を構成するのか, 光 れとも，ある $\mathrm{NC}^{k}$ より上が崩壊して階層が $\mathrm{NC}^{k}$ で押さ

\footnotetext{
* 新潟大学工学部

950-2181 新潟市五十嵐二の町 8050

Faculty of Engineering, Niigata University ,

8050 2-no-cho Ikarashi , Niigata city , Niigata 950-2181 Japan
}

えられるのかは未解決である。真の階層性を示すことは難 しいことが知られている。

$\mathrm{NC}$ と P か計算量クラスとして一致するのかどうかは未 解決問題だが, この問題は NC 階層の有限性と直接的に関 わる。もし $\mathbf{N C}=\mathbf{P}$ ならば，弚の結果として， $\mathbf{N C}$ 階層 の有限性が含意される。

〔 命題 1] $\mathrm{NC}=\mathbf{P} \Rightarrow \mathrm{NC}$ 階層は有限。

(証明)

$\mathbf{P}$ 完全問題をひとつ取りあげる。多項式時間制限された チューリング機械 ${ }^{(6)}$ は光の問題を解ける。 $\mathrm{NC}=\mathbf{P}$ なら ば, $\mathrm{NC}$ 回路も光の問題を解ける。 $\mathrm{NC} \neq \mathrm{P}$ ならば, $\mathrm{NC}$ 回路は乥の問題を解けない。

$\mathbf{N C}=\mathbf{P}$ を仮定する。 $\mathbf{P}$ 完全問題を解く $\mathbf{N C}$ 回路のひ とつは, 特定の成長率 $i$ をもつ回路の系列 $\mathrm{NC}^{i}$ になってい る。乥の成長率を越える NC 回路が行うのと同じ計算を， 产の特定の成長率のクラスの回路のひとつで行う可能性は, $\mathrm{NC}=\mathbf{P}$ と対数領域帰着が多項式時間で計算されること により保証される。

特定の成長率を越える NC 回路が行う計算は, 図 1 のよう な回路によって計算される。対数領域変換装置に対応する 回路の成長率が $i$ を越えることはない。

次節以降では, 命題 1 のもう 1 つの証明を与える。

\section{3. 回路評価回路}

〈3. 1〉 対数多項式のオーダーについて $p$ 次の多項式 は,一般に，つぎのように表される。

$$
f(x)=a_{p} x^{p}+a_{p-1} x^{p-1}+\cdots+a_{1} x+a_{0}
$$

この $f$ に対して, $\log m$ を引数として与えたものは, 対数 


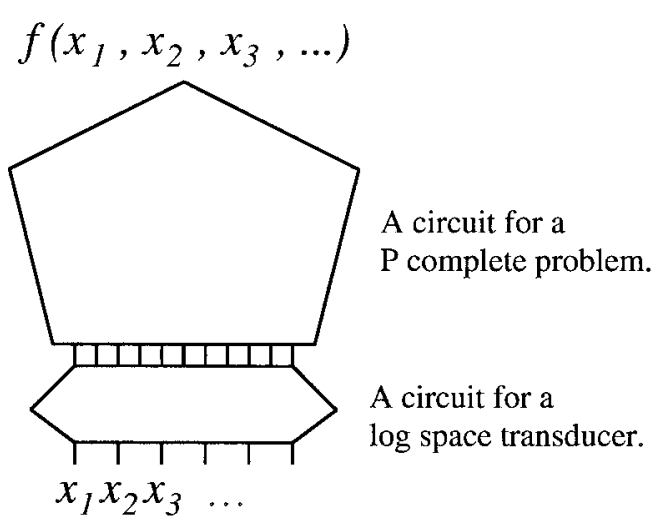

図 1 対数領域変換器に対応する回路

Fig. 1. A Circuit for a Log Space Transducer.

多項式 (poly-log expression) と呼ばれる。ここでは,計算 量の漸近的ふるまいに関心があるので, 最高次の幕だけに 注目して，オーダー表記する。

$$
f(\log m)=f \circ \log (m) \in O\left(\log ^{p} m\right)
$$

もし， $m=n^{q}$ となっている問題を考えるならば，上の 式で $f \circ \log$ によって表されている量を， $m$ に関する量とし てではなく, $n$ に関する量として捉えたいことがある。つ ぎの式は，弚のような書き換えを示している。

$$
\begin{aligned}
O\left(\log ^{p} m\right) & \ni \log ^{p} m=\log ^{p} n^{q}=\left(\log n^{q}\right)^{p} \\
& =(q \log n)^{p}=q^{p} \log ^{p} n \in O\left(\log ^{p} n\right)
\end{aligned}
$$

すなわち, $m$ が $n$ の多項式ならば,$f \circ \log$ は, $m$ に対し ても，nに対しても， $\log ^{p}$ のオーダーである。

〈3.2〉回路評価回路について 回路評価問題は, 形 式言語のひとつであり，つぎのように定義される。

$$
\{(d, x) \mid d \text { は回路 }, x \text { は } d \text { への入力 }, d(x)=1\}
$$

この言語は，P 完全問題であることか証明されている(1)。

チューリング機械を回路評価器として働かせる代わりに， 回路で回路評価を行うこともできる。产の回路を回路評価 回路 (circuit for circuit evaluation) と呼ぶことにし, 回 路系列を $\left\{C V C_{i}\right\}$ で表すことにする。ここで， $i \geq 1$ であ り, $C V C_{i}$ は入力長が $i$ の回路である。 $C V C_{i}$ は引数とし て $(d, x)$ を受け取る。式で表すと，

$$
d(x) \equiv C V C_{i}((d, x))=C V C_{|(d, x)|}((d, x))
$$

$\left\{C V C_{i}\right\}$ は，回路において生じうるすべての計算を再現 させるので, 計算装置として組み合わせ回路を選んだとき の万能計算装置である。万能回路が，ふつうの万能機械と は異なるところは, 弚れが単一の機械ではなく，あるいは， 単一の回路ではなく, 単一の回路系列か万能計算装置になっ ているというところである。わたしたちは, 単一のチュー リング機械に相当する機能を，単一の回路系列で表現する ので, 回路評価回路系列を, 回路に対する万能計算装置と 呼ぶことは, 整合している。
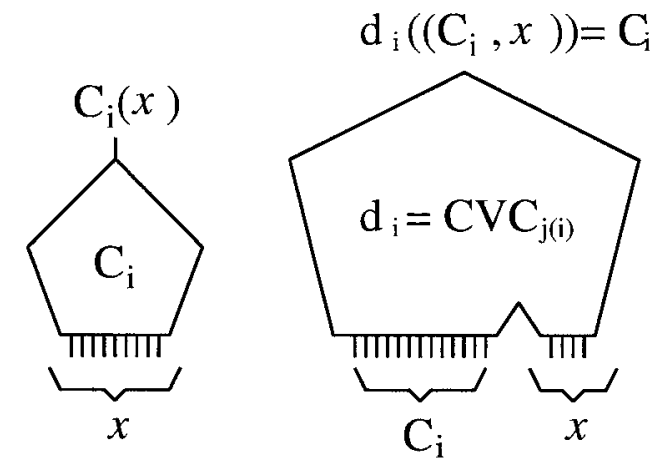

図 2 回路評価回路

Fig. 2. Circuit for Circuit Evaluation.

〈3. 3〉 $\mathrm{NC}=\mathrm{P}$ の含意 $\quad \mathrm{NC}=\mathrm{P}$ という等式が成 立すると仮定して，これが含意するものを考える。

〔 命題 2] $\mathrm{NC}=\mathbf{P}$ ならば , サイズが多項式の任意の回路 を, サイズが多項式で, 深さか対数多項式の回路へ変換 する一般的な方法が存在する。

(証明) サイズが多項式の回路系列を $\left\{c_{i}\right\}$ で表記し，光 れを変換した回路系列を $\left\{d_{i}\right\}$ で表記する。ここで， $i \geq 1$ であり, $c_{i}, d_{i}$ は入力長が $i$ の回路である。

$\left\{C V C_{i}\right\}$ に含まれる回路によって，\{cis に含まれる回路 を評価することを考える。回路評価回路は, 回路記述 $c_{i}$ と 弚れへの入力 $x$ を受け取り， $c_{i}(x)$ を計算する。つぎの恒 等式は，この性質を表している。

$$
C V C_{j(i)}\left(\left(c_{i}, x\right)\right) \equiv c_{i}(x) \text { where } j(i)=\left|\left(c_{i}, x\right)\right|
$$

これを系列全体で考えると， $\left\{C V C_{i}\right\}$ から，新しい系列

$$
\left\{d_{i}\right\}=\left\{\lambda x C V C_{j(i)}\left(\left(c_{i}, x\right)\right)\right\}
$$

をつくるということになる。图 2 は,$c_{i}$ と $d_{i}$ の関係を表現 している。

$\left\{C V C_{i}\right\}$ の計算量と， $\left\{d_{i}\right\}$ の計算量とを比較する。はじ めに , $\left\{C V C_{i}\right\}$ を示す。 $\left(C V C_{1}\right.$ などの小さい入力長の回 路評価回路は，実際には存在しない)

$$
\left\{C V C_{1}, C V C_{2}, C V C_{3}, \ldots, C V C_{i}, \ldots\right\}
$$

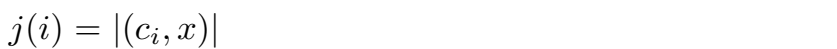
変換される。新しい系列は, 上の系列の部分集合になって いる。

$$
\left\{d_{i}\right\}=
$$

$$
\left\{C V C_{j(1)}, C V C_{j(2)}, C V C_{j(3)}, \ldots, C V C_{j(i)}, \ldots\right\}
$$

こうして得られる新しい回路系列の計算量は, $\left\{c_{i}\right\}$ と $\left\{C V C_{i}\right\}$ の計算量に依存する。いま, $\left\{c_{i}\right\}$ の計算量を size $S(i)$ and depth $D(i),\left\{C V C_{i}\right\}$ の計算量を size $S^{\prime}(i)$ and depth $D^{\prime}(i)$ とする。上にあるよう に $j(i)=\left|\left(c_{i}, x\right)\right|$ のとき, $\left|c_{i}\right| \in O(S(i))$ で, $\left|c_{i}\right|>$ $|x|$ だから,$j(i) \in O(S(i))$ となり, $\left\{d_{i}\right\}$ の計算量は 
size $S^{\prime}(j(i))$ and depth $D^{\prime}(j(i))$ となる。

$\mathrm{NC}$ 回路を考えたとき， $S(i)$ は多項式，すなわち $j(i)$ は 多項式, $D(i)$ は任意, $S^{\prime}(i)$ は多項式, $D^{\prime}(i)$ は対数多項 式という場合が，興味の対象になる。光のとき， $\left\{d_{i}\right\}$ の計 算量は, サイズは大きくなるけれども，深さは対数多項式 に押さえられる。別の言い方では, $j$ が $i$ の多項式ならば， $D^{\prime}$ は, $j$ に対しても， $i$ に対しても，対数多項式 $D^{\prime}$ のオー ダーであるとなる。

回路評価問題は $\mathbf{P}$ に属す。したがって, $\mathbf{N C}=\mathbf{P}$ とい う仮定は, 回路評価回路が NC 回路として表現できること を含意する。このとき， $\left\{d_{i}\right\}$ の深さは, $\left\{C V C_{i}\right\}$ の深さと 同じべキの対数多項式である。

$\mathbf{P}$ に属す回路評価問題が NC 回路でも計算できるとい う考えには, 興味深い性質が含まれている。弚の性質とは， 回路評価問題が対象としている回路が，構造的に制約のな い一般の回路であるにも関わらず，兴の一般の回路の評価 を，構造的な制約をもつ $\mathrm{NC}$ 回路で実行できるというもの である。この性質は， $\mathrm{NC}=\mathbf{P}$ という仮定か誤りではない かという考えを抱かせる。

$\mathbf{N C}=\mathbf{P}$ を仮定すると，回路評価回路を使って，多項式 サイズの任意の回路系列を，対数多項式の深さの回路系列 に変換できる。ここには, 回路を評価するのも回路であると いう循環がある。評価される回路は circuit $-\mathrm{P}=\mathbf{P} /$ poly

表 1 見込み評価による深さの変化

Table 1. The change of depth.

$$
\begin{array}{c|cccccccccc}
\mathrm{n} & 2 & 3 & 4 & 5 & 6 & 7 & 8 & 9 & 10 & \cdots \\
\hline d_{1}(n) & 4 & 5 & 5 & 6 & 6 & 7 & 7 & 8 & 8 & \cdots
\end{array}
$$

に属す任意の回路であり，評価する回路は $\mathrm{NC}=\mathbf{P}$ を仮 定した場合，乥の中の特定の回路である。

次節では線状回路を取り上げ，並列化の樣子を見る。

4. 線状回路の並列化について

$\mathrm{NC}=\mathbf{P}$ という仮定は, 多項式サイズの任意の一樣回路 が, NC 回路へ変形可能であることを含意する。 $\mathrm{P}$ は, 対 数領域生成される多項式サイズの一樣回路で定義されるク ラス size $n^{O(1)}(\operatorname{space} O(\log n))$ と等価なので, 変形方法 について言及することなしに, 変形可能性が成立しなけれ ばならないことは，定義からすぐにわかる。回路評価回路 による評価は, 光の变形方法になっている。

回路の変形方法を調べるにあたって，もっとも簡単に変 形できる, 対数多項式の深さではない回路として, 線状の 回路を取り上げる。ここでいう線状の回路とは, 図 3 に示 されているような，素子が線状に並んだ回路を意味する。

このような線状回路を, 対数多項式深さの回路へ変形す る。

〈4. 1〉 並列化のための分割操作 見込み評価のため に回路を半分にする。この操作全体は，つぎの各操作から なる。

（1）線状回路の深さを数える。(回路の深さを $n$ と する。)

(2) 回路を半分のところで分割する。出力側の半分が $\lfloor n / 2\rfloor$ 素子からなり，入力側の半分が $\lceil n / 2\rceil$ 素子か らなる。

（3）出力側の半分を複製する。光の結果，回路のサイ ズは $\lfloor n / 2\rfloor$ だけ増える。出力側の半分の回路と, 複

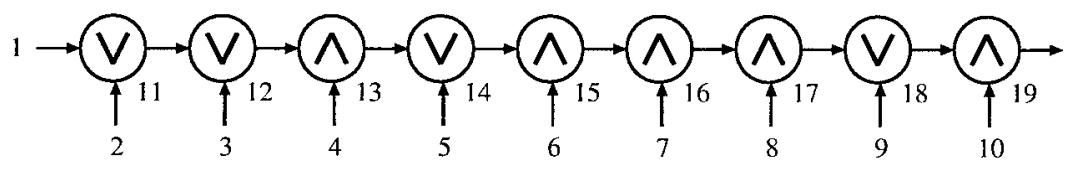

图 3 線状回路

Fig. 3. A Linear Circuit.

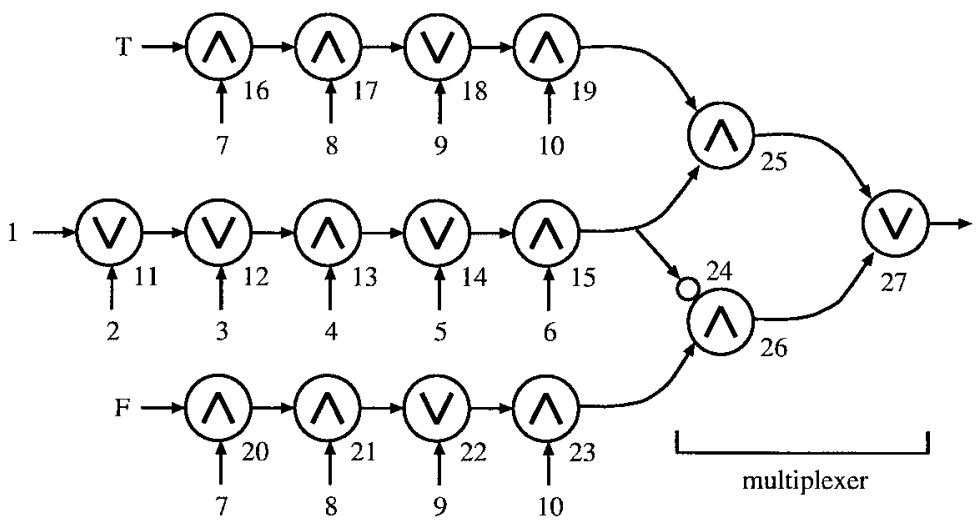

図 4 並列化された回路

Fig. 4. The Parallelized Circuit. 
製された半分の回路に，見込み值 0,1 を与える。

(4) 入力 $S$ が 1 か 0 かに応じて,$T$ か $F$ の入力を選 択して出力するマルチプレクサを割り当てる。この モジュールは素子数 4 , 深さ 3 である。

图 3 の回路を変形した結果を図 4 に示す。

このように変形された回路のサイズ $s_{1}(n)$ と深さ $d_{1}(n)$ は，

$$
s_{1}(n)=n+\lfloor n / 2\rfloor+4, \quad d_{1}(n)=\lceil n / 2\rceil+3 .
$$

$1 / 2$ の誤差を無視すれば , サイズ $n$, 深さ $n$ の回路が , 1 回 の分割で, サイズ $\frac{3}{2} n+4$, 深さ $n / 2+3$ の回路へ変形さ れる。

線状回路を並列化するとき，下の $d_{1}(n)$ に関する表が示 すように，並列化は $n \geq 8$ で意味をもつ。

〈4. 2〉並列化された回路の深さ 回路の並列化のた めに, 分割操作を再帰的に適用する。つぎの式は, $d(n)$ の 再帰的定義を示している。

$$
d(n)= \begin{cases}\mathrm{n} & : n<8 \\ d(\lceil n / 2\rceil)+3 & : \text { otherwise }\end{cases}
$$

これを非再帰的な式へ書き換える。回路の深さは, $n$ か らはじまり，分割を施すにしたがって，つぎのような系列 で深さが小さくなる。

$$
\begin{aligned}
d(n)= & \frac{n}{2^{0}}+0 \cdot 3, \\
& \frac{n}{2^{1}}+1 \cdot 3, \\
& \frac{n}{2^{2}}+2 \cdot 3,
\end{aligned}
$$

一般的には, 分割回数 $p$ に対して, $d(n)=\frac{n}{2^{p}}+3 p$ であ る。 $n=8$ が分割の基底だから,$p=\lg n-2$ となり， $d(n)$ はつぎのような式で表される対数深さになる。

$$
\begin{aligned}
d(n)= & \frac{n}{2^{\lg n-2}}+3(\lg n-2) \\
= & \frac{n}{2^{\lg n} \cdot 2^{-2}}+3(\lg n-2) \\
= & 2^{2}+3(\lg n-2)=3 \lg n-2 \\
& \quad \text { for } \quad n \geq 8
\end{aligned}
$$

〈4. 3〉並列化された回路のサイズ 次の式は $s(n)$ の 再帰的定義を示している。

$$
s(n)= \begin{cases}\mathrm{n} & : n<8 \\ \underbrace{s(\lceil n / 2\rceil)}_{\text {入力側の半分 }}+2 \underbrace{s(\lfloor n / 2\rfloor)}_{\text {出力側の半分 }}+4 & : \text { otherwise }\end{cases}
$$

前節と同じように，この式を非再帰的な閉じた式へ書き 換える。关の際，切り上げ関数，切り下げ関数は無視する。 すなわち,$s(\lceil n / 2\rceil)+2 s(\lfloor n / 2\rfloor)=(3 / 2) \cdot s(n / 2)$ とする。 回路のサイズは $n$ からはじまり, 分割を施すにしたがって , つぎのような系列でサイズが大きくなっていく。

$$
\begin{aligned}
s(n)= & (3 / 2)^{0} n, \\
& (3 / 2)^{1} n+4 \cdot 3^{0}, \\
& (3 / 2)^{2} n+4 \cdot 3^{0}+4 \cdot 3^{1}, \\
& (3 / 2)^{3} n+4 \cdot 3^{0}+4 \cdot 3^{1}+4 \cdot 3^{2},
\end{aligned}
$$

分割の回数を $p$ とすると，一般的には，

$$
s(n)=\left(\frac{3}{2}\right)^{p} n+4 \sum_{k=0}^{p-1} 3^{k}=\left(\frac{3}{2}\right)^{p} n+4 \cdot \frac{1}{2}\left(3^{p}-1\right) .
$$

$p=\lg n-2$ を代入する。

$$
\begin{aligned}
s(n)= & \left(\frac{3}{2}\right)^{\lg n-2} n+4 \cdot \frac{1}{2}\left(3^{\lg n-2}-1\right) \\
= & \frac{3^{\lg n-2}}{2^{\lg n} \cdot 2^{-2}} n+2\left(3^{\lg n-2}-1\right) \\
= & 4 \cdot 3^{\lg n-2}+2\left(3^{\lg n-2}-1\right) \\
= & 6 \cdot 3^{\lg n-2}-2 \\
= & 2 \cdot 3^{\lg n-1}-2 \\
& \text { for } \quad n \geq 8
\end{aligned}
$$

異なる底を関係づける等式 $3^{x} \equiv 2^{(\lg 3) x}$ を使って，底が 2 の表現へ書き換えると，これが $O\left(n^{\lg 3}\right)$ の関数であること がはっきりする。

$$
\begin{aligned}
s(n) & =2 \cdot 2^{(\lg 3)(\lg n-1)}-2 \\
& =2 \cdot 2^{(\lg 3) \lg n} \cdot 2^{-(\lg 3)}-2 \\
& =2 \cdot 2^{\lg n^{(\lg 3)}} \cdot(1 / 3)-2 \\
& =(2 / 3) \cdot n^{\lg 3}-2 .
\end{aligned}
$$

$1<\lg 3<2$ だから , $n$ が大きいところで $n<n^{\lg 3}<n^{2}$ という関係になる。

この変形は, 回路のサイズを大きくするけれども, 深さ が小さくなるので, 回路は”並列化”される。サイズが $n$ の線状回路を並列化して得られる回路の計算量は, 切り上 げ関数, 切り下げ関数を無視しているので, おおよ关深さ $d(n)=3 \lg n-2$ ，サイズ $s(n)=(2 / 3) \cdot n^{\lg 3}-2$ となる。 線形深さが対数深さになり, サイズは $n$ から $n^{\lg 3}$ のオー ダーの量に増えている。

\section{5. むすび}

$\mathbf{P}$ 完全な問題である回路評価問題に注目して， $\mathrm{NC}=$ $\mathbf{P} \Rightarrow \mathbf{N C}$ 階層は有限という命題を証明した。したがって， $\mathbf{N C}$ 階層が無限ならば， $\mathbf{N C} \neq \mathbf{P}$ となる。 $\mathbf{N C}=\mathbf{P}$ のと き, 回路評価問題は並列化手続きとして働くという奇妙な 性質を示す。回路評価問題を解く回路が他の問題を単にシ ミュレートすることによって，いわば自動的に並列化され る。このことは, $\mathbf{N C} \neq \mathbf{P}$ であることを示唆する。

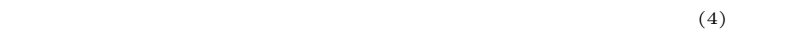
同樣に成立する。 $\mathrm{NC}=\mathrm{P}$ のもとでは, 非一樣な回路の並 
列化も可能になり, 多項式サイズ, 深さ無制限の回路族は, 多項式サイズ , 対数多項式深さの回路族へと変換可能にな る。この事実は，NCのような一樣回路での証明を考える 代わりに , 非一樣回路での証明を考えても， $\mathbf{N C} \neq \mathbf{P}$ の証 明になるということを示している。

(平成 16 年 10 月 21 日受付, 平成 17 年 8 月 8 日再受付)

\section{文献}

(1) R.E. Ladner: "The circuit value problem is log space complete for P", SIGACT News, Vol.7, pp.18-20 (1975)

(2) Michael Sipser: "Introduction to the Theory of Computation", PWS Publishing Company (1997) 日本語訳 : 渡辺治ほか訳, 計算理論の基礎, 共立出版 (2000)

( 3 ) Nicholas Pippenger: "On simultaneous resource bounds", In San Juan, editor, Proceedings: 20th Annual Symposium on Fundations of Computer Science, pp.307-311 (1979)

(4) J.L. Balcázar, J. Díaz, and J. Gabarró: "Structual Complexity", Vol.I, II of EATCS Monographs on Theoretical Computer Science. Springer Verlag, (1988), (1990) 日本語訳 : (I のみ) 足立暁生訳, 構造的計算量理論, シュプリンガ・ フェアラーク東京 $(1989)$

(5) R. Greenlaw, H.J. Hoover, and L.W. Ruzzo: "Limits to Parallel Computation: P-Completeness Theory", Oxford University Press (1995)

(6) J.E. Hopcroft and J.D. Ullman: "Introduction to Automata Theory, Languages and Computation", AddisonWesley (1979)

日本語版：野崎昭弘ほか訳，「オートマトン・言語理論・計算論 1 , 同 2.」サイエンス社 (1984), (1986)

清 野 克 宏 (非会員) 2001 年新潟大学工学部情報工学科卒。

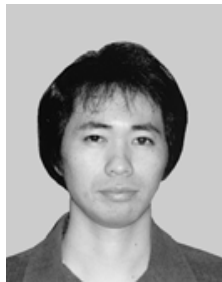
2004 年同自然科学研究科情報・計算機工学専攻 博士前期課程修了。工学修士。

田中

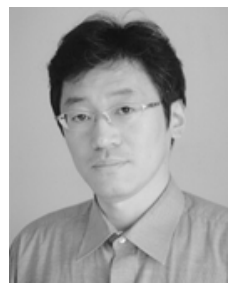

賢 (正員) 1989 年早大·理工・電気卒。1991 年東工 大・総合理工・システム科学修士課程了。1995 年 東工大·理工・情報工学博士課程単位取得。2002 年新潟大学大工学部情報工学科講師。博士 (情報 科学)。情報処理学会会員。 